\title{
Do quarto de despejo à sala de estar: aventuras de uma obra pelo campo literário
}

\begin{abstract}
Resumo:
Este trabalho pretende indagar sobre certas implicações da presença no mercado editorial de uma narrativa como Quarto de despejo: diário de uma favelada, de Carolina Maria de Jesus, à luz da noção de campo literário, formulada por Pierre Bourdieu. A discussão adquire relevância por esse discurso, apesar de advir de um espaço historicamente desprestigiado, uma favela brasileira, negociar e disputar sua entrada e permanência no cenário da
\end{abstract} \\ cultura letrada.
}

Luciara Pereira

Mestranda - UFSM

Palavras-chave: Narrativa; sujeito subalterno; campo literário

A aproximação ao fenômeno literário tem cobrado mudanças na posição assumida pelo crítico, na medida em que as produções indiciam a imersão num momento de instabilidades de princípios analíticos, interpretativos e valorativos, gerado principalmente pela multiplicidade de personagens culturais. Diante disso, as abordagens tradicionais, restritas ao texto ou ao contexto social, não vislumbram a extensão dos elementos que gravitam junto à obra literária. À luz dessas dicotomias, Pierre Bourdieu (1996) integra ao debate teórico a noção de campo literário, contribuindo para a tentativa de compreensão da obra nas suas condições sociais de produção nas suas múltiplas relações e tensões, dadas pela estrutura e pela ação dos agentes no campo num determinado momento.

O campo literário contempla um espaço no qual se travam relações objetivas de concorrências, disputas e negociações entre diferentes agentes, cujas posições e tomadas de posição respondem a fatores como trajetórias pessoais e sociais, disposições e escolhas dentro dos espaços dos possíveis. Seria, portanto, uma instância mediadora entre as esferas social e textual, que, apesar de ter uma autonomia relativa frente a outros campos (político, econômico, etc.), sofre interferências que se refletem na organização e na convivência dos elementos que o integra.

Em decorrência da constante possibilidade de reformulação de sua constituição, não há fixidez de paradigmas, valores ou posições, pois as negociações formam uma rede relacional na qual qualquer modificação em algum aspecto interno ou externo ao campo altera sua estrutura. Compreendê-lo implica, então, primeiro, dar conta das condições de produção e das disposições dos espaços dos possíveis, que situam e orientam uma 
tomada de posição perante os demais agentes do campo, visando à disputa pela legitimação.

O campo se organiza, pois, sob a égide de um conjunto de regras que determinam a entrada e o investimento no jogo, o qual se articularia em torno da crença na possibilidade de reconhecimento e, com isso, a obtenção do poder e da autoridade sobre seus agentes, situação que admitiria, para Bourdieu, a ideia de illusio. As apostas são feitas vislumbrando a adesão de um receptor que aceite o protocolo de valor atribuído à obra e à posição do autor, apostas que dependem das disposições do campo e do habitus, correspondente a um conjunto de predisposições, valores, formas de pensar e de perceber reguladores das relações numa estrutura social.

Esse quadro dinâmico de (re)articulação cultural sugere a presença da figura do emergente, implementada por Raymond Williams (1980), pois, na medida em que o sujeito assume uma postura, precisa compreender e se ajustar às regras na possibilidade de, então, subvertê-las. A condição de emergência implicaria justamente um processo de negociação, adesão, modificação ou substituição das normas e valores que regem o campo.

Assim, para depreender as consequências da posição assumida pela obra e principalmente do processo que a conduziu a esta situação, é preciso pensar nas condições internas e externas do campo literário. Portanto, para compreender a publicação de uma obra como o diário Quarto de despejo, da favelada Carolina Maria de Jesus, de 1960, é essencial, em primeira instância, resgatar as circunstâncias históricas que possibilitaram sua circulação, situando e percebendo como elas se relacionam ao seu percurso particular. Isso porque se trata de um texto que põe em cena uma série de indagações pela sua origem periférica e pelas tentativas de adentrar no espaço literário.

Parece válido, nessa perspectiva, revisar as condições político-econômicas que teriam influenciado de maneira direta o campo artístico, em particular o literário, na época em que o diário foi publicado. Nesse momento, anos 1950 e 1960, a política de Juscelino Kubitschek promete um desenvolvimento prodigioso, desencadeando uma efervescência tanto política como cultural. Torna-se manifesto um intenso processo de industrialização que acentua, sobretudo, a migração aos grandes centros, imprimindo outro aspecto a suas paisagens. Formam-se, com isso, aglomerados humanos que passam a constituir e ampliar as favelas, como a do Canindé, situada às margens do Tietê, na cidade de São Paulo, hoje extinta. Assim, há um aumento na disparidade social, deixando os grupos periféricos à margem de todo esse processo de modernização, o que inevitavelmente provoca descontentamento.

A presença desse periférico que rompe as fronteiras entre a favela e a cidade provoca desconforto no olhar do outro hegemônico. A cidade começa a mostrar cenários urbanos que desagradam pela miséria, desordem e marginalidade crescentes. Entretanto, esse outro espaço consolida certos grupos humanos, como o dos favelados que, por sua vez, produzem outro tipo de experiência social.

Interessa destacar desse quadro de expansão da favela a consolidação de novas formas de expressão de um grupo emergente. Conforme Raymond Williams, "una nueva clase es siempre una fuente de una práctica cultural emergente, aunque mientras como clase todavía se halla relativamente subordinada, siempre es susceptible de ser desigual y con seguridad es incompleta, ya que la nueva práctica no es en modo alguno un proceso aislado". ${ }^{1}$ Haveria, portanto, um sistema de disposições que permitiria a emergência de Carolina Maria de Jesus, amparado pelo surgimento de um novo grupo

\footnotetext{
${ }^{1}$ WILLIAMS. Marxismo y literatura, p. 146-147.
} 
social e pelas condições histórias, econômicas e tecnológicas em processo de "democratização".

A poeta do lixo entra em cena no campo literário como uma posição emergente, surgida em meio à imundice e que, com sensibilidade particular, passa a registrar o cotidiano desse espaço "outro". É uma favelada, catadora de papel, negra, semianalfabeta, que traduz pela palavra escrita seu cotidiano de mulher periférica, revelando sob sua perspectiva a rotina e a condição social de um grupo rejeitado pelo olhar hegemônico.

Isso se torna possível, por outro lado, pelas condições culturais e tecnológicas em expansão, que, dentre outros, indiciariam a inserção num outro momento histórico, regido por outra lógica cultural, denominada por alguns como pós-modernidade. Gianni Vattimo (1989) destaca que uma das consequências do suposto fim da modernidade seria a "caída [d]a idéia de uma racionalidade central da história, o mundo da comunicação generalizada explode como uma multiplicidade de racionalidades 'locais' minorias étnicas, sexuais, religiosas, culturais ou estéticas - que tomam a palavra". ${ }^{2}$ Para o autor, o advento dos mass media teria possibilitado a ampliação do público e seu acesso a esses meios, veiculando diferentes produções advindas de grupos antes mantidos à margem do processo cultural hegemônico. Diante disso, a sociedade contemporânea é invadida por inúmeras histórias nas quais o outro desconhecido sobe ao palco para revelar seu cotidiano e sua experiência.

Ao encontro dessa formulação, Beatriz Sarlo considera que a formalização de narrativas centradas no resgate de eventos relacionados ao patrimônio de determinados grupos até então privados da palavra, responde a um momento que vuelve como cuadro de costumbres donde se valoran los detalles, las originalidades, la excepción a la norma, las curiosidades que ya no se encuentram en el presente. Como se trata de la vida cotidiana, las mujeres (especialistas en esa dimensión de lo privado y lo público) ocupan una porción relevante del cuadro. ${ }^{3}$

A diferença e o cotidiano adornado de "detalhes" e "exceções" convertem-se em protagonistas dessas narrativas, na medida em que revelam o sistema de relações e percepções particulares na formação de um grupo e no confronto com outros.

Ora, a emergência de Carolina Maria de Jesus não teria se efetivado apenas pela visibilidade que o favelado adquire no contexto urbano, ou o advento dos mass media. Nesse caso, sobretudo em função de sua condição subalterna, a intervenção do jornalista Audálio Dantas é determinante para que consiga se integrar ao campo. Sozinha, ela não dispunha de "requisitos" suficientes para assinar os protocolos e chegar ao meio editorial.

É relevante assinalar que sua incursão pelo meio letrado só foi possível, no primeiro momento, pela intervenção de um sujeito habituado com o funcionamento desse sistema, que agencia sua circulação, não sem gerar impasses e contradições. Por um lado, o jornalista é fundamental para a publicação, por outro, após a recepção do livro, sua presença gera desconfiança e torna-se importuna, sobretudo quando se verificam os constantes cortes realizados no texto, indicados pelos três pontos (...): "Estava nervosa interiormente, ia maldizendo a sorte (...) Catei dois sacos de papel. ${ }^{\prime 4}$

Esses cortes denunciam a tentativa de adequar o texto a determinado modelo da cultura letrada, bem como a um tipo de leitor que supostamente não tem "tempo" nem paciência para a repetitividade presente nos originais, "a repetição da rotina favelada,

\footnotetext{
2 VATTIMO. A sociedade transparente, p. 17.

${ }^{3}$ SARLO. Tiempo pasado: cultura de la memoria y giro subjetivo. Una discusión, p. 10.

4 JESUS. Quarto de despejo: diário de uma favelada, p. 10.
} 
por mais fiel que fosse, seria exaustiva. Por isso foram feitos cortes, selecionados os trechos mais significativos". Com isso o mediador castra o próprio sentido do diário, da rotina desgastante, exaustiva e sofrida vivida pela autora naquele espaço.

Pensando na sua posição de jornalista, indaga-se sobre seu possível interesse em mediar essa obra. Assim, o diário parece ter para Audálio Dantas um caráter de "furo de reportagem", um interesse expressamente documental, o que talvez justifique os cortes efetuados sobre as ações repetidas de Carolina, atentando para as representações dos conflitos e dos acontecimentos da favela. Com isso, a rotina da "narradora-protagonista" deixa de ser a personagem central da narrativa, para dar ênfase à favela.

Independente de seus interesses, o ato de mediação e de ajuste do texto parece conferir certa relevância à narrativa, mas não necessariamente em termos literários. $\mathrm{Na}$ edição de 2006, Dantas salienta a pertinência social: "não é um livro de ontem, é de hoje", e autêntica do texto: "escritor nenhum poderia escrever melhor aquela história". Nem mesmo ele parece crer no suposto valor literário do livro, pois atribui um "valor" documental, mesmo passados quarenta anos. Porém, que tipo de poder esse sujeito dispõe para julgar ou legitimar no campo literário essa narrativa, sendo ele um jornalista? Por outro lado, a relevância do diário ainda hoje, mesmo em nível social, não seria um indício de que o texto não é simplesmente uma "reportagem"?

A mediação, independente das implicações de sentido e da série de impasses desencadeada, configura-se como um elemento agenciador entre o texto de Carolina e o mercado editorial. Sem essa negociação, que se dá também com o leitor, e sem a contundência em se falar da favela naquele momento, o livro dificilmente seria publicado. Sua presença explicita o processo intrínseco ao campo: o negociar. Embora haja visíveis desacordos entre as duas figuras envolvidas, Carolina Maria de Jesus e o jornalista, Quarto de despejo parece ter, para cada um, interesses específicos, sendo um deles comum aos dois: a busca pela legitimação: ela enquanto escritora, e ele como jornalista, pois a edição permitiria sua circulação escrita por outras vias.

A presença das problemáticas referidas, dentre outras, instaura uma série de discussões teóricas e críticas, na medida em que quer circular como literatura, mas não corresponde aos paradigmas da arte moderna que, apesar de supostamente estarem em crise, ainda se fazem presentes quando se julga uma obra. Uma das questões mais polêmicas seria a que diz respeito à dimensão que assume análoga à literatura de massa, tanto pela "divulgação" em meios de comunicação massivos, submetida supostamente à lógica do mercado editorial, como pelo teor documental, que se aproximaria ao efêmero consumo da informação.

De acordo com esse quadro, podem ser feitas algumas indagações pertinentes: quais fatores são julgados para conceber ou desconsiderar o diário como parte do campo literário? Sua índole documental? Sua circulação por meios de comunicação massivos, parecendo se sustentar sob princípios da literatura de massa? Por outro lado, sua presença no campo como uma posição emergente teria poder para desestabilizar e inverter os valores estabelecidos?

Responder ao questionamento de quais aspectos objetivos permitiriam ou não o reconhecimento de uma obra como literária, principalmente esta, exige percorrer um longo e incerto caminho. A legitimação de uma obra depende cada vez mais do acordo entre grupos particulares detentores do poder de julgar em função de sua posição privilegiada e das predisposições admitidas pelo campo. Terry Eagleton (2006) argumenta que identificar o estatuto literário de uma obra depende das circunstâncias contextuais e do acordo estabelecido com o grupo dominante. Para o autor, essa definição não depende dos aspectos internos à obra, como o arranjo lingüístico, mas do "clima" sociocultural orientado pelos detentores da autoridade sagrada de julgar. 
Quarto de despejo, nesses termos, representa um problema para a crítica literária, visto que foge dos paradigmas literários canônicos: teor documental; condição subalterna da autora; impasses gerados pelo processo de escritura do texto; presença de um mediador letrado, dentre outros. Em função disso, foi recebida, num primeiro momento, como o relato de experiências "autênticas", ignorando as implicações de uma manifestação que representa uma identidade cultural e almeja um espaço no campo literário. Essas tensões perpassam todo o percurso da obra, desde a emergência até sua circulação.

\section{UMA POSIÇÃO EM EMERGÊNCIA}

A procedência social de Carolina aliada à conversão do cotidiano e da experiência periférica em conteúdo narrativo de um texto de índole documental desencadeia uma forte carga semântica "marginal", que gravita em torno de sua figura de emergente subalterna. Tal condição dificulta sua inserção no campo, gerando um estranho paradoxo: por um lado sua obra é publicada e lida justamente por ser uma favelada dando seu testemunho, alicerçado sob experiências cotidianas relacionadas àquele espaço. Por outro lado, sua condição de subalterna a impede de circular como literatura, não permitindo que ela se estabilize e se legitime como escritora consagrada.

Sua origem seria, em primeira instância, um critério que garantiria a "autenticidade" do conteúdo e da voz narrativa, respondendo à ideia de veracidade dos fatos. Entretanto, não se pode perder de vista a problematização de Henry Lefebvre (2006) sobre a natureza da representação. Representar um "real" não elimina o processo de elaboração dessa imagem. A própria autenticidade seria, conforme o autor, uma representação eficaz que gera um efeito de, pois entre o real e o livro há o processo de organização que implica uma perspectiva pessoal e o trabalho com mecanismos específicos da linguagem. Teresa Cabañas (2006) destaca esse "equívoco" nas abordagens que consideram apenas o conteúdo dessa narrativa, ignorando os aspectos formais que sustentam esse efeito.

A representação da favela, formalizada por Carolina Maria de Jesus, não apresenta a realidade imediata, mas o que a autora percebe, seleciona e constrói enquanto sua "realidade" pela escrita. É uma representação calcada na experiência, no "real", mas isso não elimina o trabalho de elaboração narrativa e discursiva. Tal esclarecimento também vale para a instância discursiva presente na narrativa, pois o sujeito empírico Carolina Maria de Jesus não coincide com a categoria projetada no texto como narradora e, ainda, com a protagonista dos fatos narrados. Segundo Verena Alberti (1991), as narrativas autobiográficas apresentariam, no nível do discurso, três categorias, "dentro do texto, narrador e personagem remetem, respectivamente, ao sujeito da enunciação e ao sujeito do enunciado: o narrador narra a história e o personagem é o sujeito sobre o qual se fala. Ambos, porém, remetem ao autor, que passa a ser o referente, fora do texto" (grifos nosso).

A autenticidade não seria, pois, a fidelidade ao real, ainda mais que entre o texto de Carolina e a publicação final se coloca a figura do mediador, atuando como um dos agentes em busca da legitimação da obra no campo literário, o qual evidentemente não age sozinho. Junto a ele, o texto elaborado pela autora se apropria de mecanismos próprios do campo hegemônico, dos quais ela faz uso de maneira nada ingênua. Dentre essas estratégias, o uso de um gênero textual institucionalizado pela esfera hegemônica, o diário, é essencial, embora gere uma série de impasses na escritura e nos elementos que tenta aliar. 
O texto revela ainda uma escrita ambígua e desajustada, com a inserção de termos pouco usuais, que destoam violentamente da sua linguagem rudimentar, vinculada a uma cultura sustentada pela palavra falada. Todavia, apesar de gerarem certo tipo de estranhamento, representam a relação dessa subalterna com a escrita e o conflito que esse sujeito vive frente à esfera hegemônica.

Apesar dos olhares desconfiados e avessos, Quarto de despejo tomou uma considerável fatia do mercado editorial. Porém, ainda hoje se tem questionado a que gesto sua emergência corresponde: Uma presença insignificante para o conjunto de obras já estabelecido? Uma tentativa de subversão? Um índice de um processo de transição, talvez para uma outra lógica cultural?

A publicação do diário, aliada ao conjunto de estratégias de inserção no campo literário, revela o imbricamento entre os elementos que formam o campo, do qual a autora tem consciência e com os quais tenta negociar, sobretudo pela apropriação de certas convenções "tradicionais", invadindo assim espaços nas prateleiras que antes eram predominantemente canônicos.

\section{UM PERCURSO EM BUSCA DA INSTITUCIONALIZAÇÃO}

O percurso histórico da obra revela de maneira exemplar a própria dinâmica do campo literário. Ilustra como a convergência das disposições históricas, dos agentes e principalmente dos leitores, em decorrência da modificação das predisposições sociais ligadas à noção de habitus, alteram a maneira como a obra é recebida, pois ela teria passado a corresponder ao conjunto de expectativas e ao espírito de um outro momento histórico-cultural.

O próprio jogo passa a se estabelecer de maneira distinta. O grupo de leitores previsto no momento da publicação não é o mesmo de hoje, no século 21 . Naquele período, apesar de Carolina Maria de Jesus desejar se legitimar como autora, a forma como ela se integra ao campo a faz ser vista como literatura de massa. Portanto, corresponderia às expectativas de um grupo de leitores específicos ou, neste caso, consumidores.

É interessante perceber que o texto permanece o mesmo; entretanto, a forma como tem sido lido é distinta, sobretudo por um público capaz de legitimar sua posição privilegiada no campo como parte do corpus da literatura brasileira. Ainda mais que hoje esse texto tem sido constantemente referido como um importante antecedente para compreender a emergência de narrativas e textos similares. Para Bourdieu, esse é o sentido do jogo, a busca da legitimação processada pelo interesse de certos grupos de leitores sobre a obra, permitindo sua consolidação pelos acordos e pelas apostas investidas, decorrentes da crença coletiva na illusio. Daí a importância do aval dado por certa crítica acadêmica.

Em 1960, a publicação de Quarto de despejo é antecedida por um processo de divulgação que cria uma expectativa sobre a obra. Primeiramente, Audálio Dantas publica partes do diário no jornal Folha da Noite e na revista O Cruzeiro, na qual trabalhava como jornalista. Sua receptividade inicial responde a uma curiosidade enquanto registro documental e sociológico. Hoje esse texto tem sido amplamente referido, mas o que teria motivado essa mudança frente a ele? As condições históricas que permitiram a ampliação do cenário da favela e sua maior participação no campo cultural? Ou o livro apresentaria algo relevante para os estudos literários contemporâneos, possibilitando talvez a compreensão de um fenômeno de multiplicidade de vozes em emergência? 
Bourdieu assinala que o leitor do livro seria uma das categorias fulcrais que levaria ao reconhecimento de uma obra. Ciente disso, a autora sabe que não escreve para seus pares, pois no texto ela já indica um possível leitor, desvinculado do espaço da favela, "há de existir alguém que lendo o que eu escrevo dirá (...) isto é mentira! Mas, as misérias são reais". ${ }^{5} \mathrm{O}$ interesse do público leitor sobre o texto se acentua em razão do protocolo firmado de que tais experiências foram formalizadas por alguém que as viveu, e mais, o fato incomum de um subalterno se revelar pelos mecanismos da escrita. Tais aspectos se tornam centrais para a discussão sobre o testemunho e o sentido de denúncia que se realizará anos depois no mundo hispano-americano.

A trajetória de Quarto de despejo demonstra como o olhar sobre um texto depende das condições, do "clima" de uma época e da receptividade de um grupo social ou intelectual. Por isso, num dado momento descartam seu texto, mas hoje, diante de um acentuado aumento de publicações da mesma natureza, canonizou-se como uma obra precursora desse fenômeno, sendo constantemente retomada na tentativa de compreender a que se deve esse "assalto ao poder da escrita" ${ }^{6}$ e a crescente circulação, ainda vista com maus olhos pelos guardiões do cânone.

\section{CONSIDERAÇÕES FINAIS}

O campo literário configura-se por relações de poder, tanto de manutenção, por aqueles que detêm a posição dominante, quanto de subversão, por figuras emergentes que almejam a consolidação de uma posição privilegiada. A inserção de qualquer obra se dá a partir de um processo de negociação entre os diferentes agentes e mecanismos que incidirão na tomada de posição e na própria reconfiguração do campo. A negociação não se põe em termos meramente de possibilidade, mas de necessidade, uma vez que, para manter a hegemonia, é necessário negociar com o outro, oferecer vantagens e estabelecer paradigmas de "controle" que, ao mesmo tempo em que permitem sua entrada, preservam a detenção do poder. Para Raymond Williams, "todo proceso hegemónico debe estar en un estado especialmente alerta y receptivo hacia las alternativas y la oposición que cuestiona o amenaza su dominación. La realidad del proceso cultural debe incluir siempre los esfuerzos e las contribuciones de los que de un modo $u$ otro se hallan fuera o al margen de los términos que plantea la hegemonía específica. $^{7}$

O livro de Carolina Maria de Jesus se integra a esse processo de negociação desde o momento da escolha de um formato textual institucionalizado (diário), que admite maior credibilidade para determinado grupo de leitores que leem textos correspondentes ao paradigma literário legitimado. Além dessa implicação, tal gênero favorece a intensidade e o efeito realista com que aquele cotidiano é revelado em sua repetitividade dada pela perspectiva diária de um sujeito que destaca os acontecimentos mais relevantes de sua rotina. Na condição de emergente, Mukarovsky refere que as produções das margens se valem das normas dominantes para se integrar ao jogo e poder posteriormente impor sua posição pela adequação dessa norma a uma expressividade própria. Assim, o diário é uma forma de se integrar ao campo literário, mas também responde a outras funções em nível pragmático, como arma de defesa e de ascensão social.

\footnotetext{
${ }^{5}$ JESUS. Quarto de despejo: diário de uma favelada, p. 41.

${ }^{6}$ VILLARRAGA. Literatura marginal: o assalto ao poder da escrita.

${ }^{7}$ WILLIAMS. Marxismo y literatura, p. 135.
} 
Isso se deve basicamente à mutabilidade da norma, que encerra em si a possibilidade de subversão, recriação, exclusão e resgate, de acordo com os interesses dos agentes em emergência, orientados pelas disposições e pelo movimento do campo: "la norma no pierde su valor de manera real e irreparable, puesto que por lo general no se trata, por parte de la capa inferior, de adoptarla pasivamente, sino de recrearla activamente a la vista de la tradición estética del medio dado y del conjunto total de todos los tipos de normas válidas para este medio". ${ }^{8}$

A partir da noção de campo já referida, a obra não teria como se isentar de sua pertença social e histórica e da relação de interferência recíproca. Quarto de despejo traz à luz uma imagem do favelado que em certa medida desnaturaliza seu estereótipo ao revelar o lado "humano" desse sujeito marcado pela marginalidade. Além disso, representa um sensorium particular, uma forma outra de perceber o mundo, alicerçada sob a formação de uma identidade estética. Para Jesús Martín-Barbeiro (1997), o valor do popular está na capacidade de materializar e de expressar o modo de viver e de pensar das classes subalternas, configurando seu repertório simbólico. Assim, Carolina Maria de Jesus manifesta uma forma particular de perceber o mundo por meio de um arranjo linguístico repleto de uma percepção e uma sensibilidade individual e coletiva.

Nesse contexto cultural, sinalizado pela publicação do diário, parece haver um crescente interesse na periferia como fonte de produções culturais hegemônicas, não só no campo literário, mas no musical, artístico, cinematográfico e televisivo. João Cezar de Castro Rocha (2004) considera que tal atenção, camuflada de "abertura" para os subalternos, seria uma forma de exploração das manifestações culturais e identitárias dos espaços marginais, sem, entretanto, mudar sua situação.

Gianni Vattimo (1989), por sua vez, vê isso como certa democratização dos meios e como uma flexibilização do campo, conferida pelo interesse perante a experiência cotidiana do outro. Essa postura me parece ser mais coerente, na medida em que o processo de negociação implica uma troca, e não benefícios exclusivos a uma das partes interessadas. Para o mercado cultural, possibilitaria a ampliação de seu público, já para as minorias, permite a disputa por um espaço e seu respectivo reconhecimento no território simbólico.

A emergência de novas condições históricas assinala, portanto, a emergência de outro olhar sobre o mundo e uma nova forma de percebê-lo e de se relacionar com ele. Essas representações traduzem a condição do homem frente a um universo de negociações, de busca pela emergência social e de impasses desencadeados pela condição de subalternidade. Diante disso, o "diário" de Carolina ilustra o funcionamento do sistema social e do campo literário: o constante negociar frente às relações de poder, de dependência, de busca pela autonomia e de reconhecimento social e cultural.

A questão que se coloca perante a situação esboçada é a de como conceber essas obras provindas de espaços historicamente marginalizados e que carregam em si uma série de problemas porque colocam em xeque muitos dos paradigmas modernos da arte? De quais procedimentos de aproximação o estudioso pode se valer para dar conta desses textos? Acredito que hoje, frente a essa abertura editorial, seja pertinente falar na existência não somente de um cânone, mas de conjuntos de obras vinculadas a diferentes "tribos" que reivindicam o teor artístico de suas formas de representatividade, correspondendo a diferentes momentos, espaços e leitores. São materialidades expressivas que têm sua relevância como obras estéticas e como manifestações culturais que revelam muito sobre um olhar acerca do mundo. Isso acaba gerando outro impasse

\footnotetext{
${ }^{8}$ MUKAROVSKY. Escritos de estetica y semiotica del arte, p. 75.
} 
na postura do crítico. Cabe a ele valorar? Mas a partir de quais paradigmas, já que há uma coexistência de produções que não permite se pensar num espírito comum?

A presença de Carolina Maria de Jesus no campo, já nos anos 1960, incidiu de maneira estrondosa, mas efêmera. Hoje, porém, acompanhando o processo históricocultural, percebe-se que sua emergência não foi gratuita. Ela corresponde a um sistema de possibilidades advindas de um espaço dos possíveis (Bourdieu), da variabilidade e mutabilidade de uma norma (Mukarovsky); e da dinâmica do processo cultural a partir das relações estabelecidas entre as categorias do emergente, residual e dominante (Williams), que, com isso, admite uma constante renovação dentro de uma "tradição", assegurando a vigência de um processo que é cultural, mas também social, histórico e sensível. A publicação dessa narrativa não seria algo inconcebível, mas o resultado ou início de um processo que ainda está se definindo e por isso não se pode recusar sua existência, uma vez que isso levaria à estagnação dos estudos literários e ao cultivo eterno de normas e valores que não corresponderiam mais ao sensorium e à dimensão humana de uma época.

O "diário" expressa as condições sociais e humanas de um momento vivido por um grupo humano que tem ultrapassado os limites da periferia e que reivindica a condição de sujeito da própria escrita, possibilitando a tomada da palavra para representar a si mesmo, amenizando a histórica dependência cultural. Apesar da hierarquização literária, não se pode ignorar ou descartar certos fenômenos sem compreender sua dinâmica e

seu sentido. Essa narrativa diz algo sobre aquele momento e sobre aquele grupo de acordo com as estratégias e as possibilidades de que a autora dispõe para os representar. Mesmo sendo aparentemente limitadas e "deficientes", revelam a própria relação conflituosa e desajustada que essa mulher favelada estabelece com seu mundo e com o espaço ao qual ela procura se integrar, a partir de uma série de disputas e negociações que precisa estabelecer para transitar do quarto de despejo à sala de estar.

Abstract:

This work aims at investigating the implications of the presence of Quarto de despejo: diário de uma favelada (Child of the dark), by Carolina Maria de Jesus, in the publishing market. To do so, the notion of literary field elaborated by Pierre Bourdieu is taken into account. This discussion becomes even more relevant as the above-mentioned discourse negotiates and disputes its entrance and its permanency in the erudite culture scene although it comes from a historically underprivileged space such as a Brazilian slum.

Keywords: Narrative; subordinate subject; literary field

Referências

ALBERTI, Verena. Literatura e autobiografia: a questão do sujeito da narrativa. Estudos Históricos. Rio de Janeiro, v. 4, n. 7, p. 66-81, 1991. 
BOURDIEU, Pierre. Razões práticas: sobre a teoria da ação. Campinas: Papirus, 1996.

BOURDIEU, Pierre. As regras da arte: gênese e estrutura do campo literário. São Paulo: Companhia das Letras, 1996.

CABAÑAS, Teresa. Da representação à representatividade: quem legitima: provocação ao debate. Revista de Crítica Literária Latinoamericana, Lima-Hanover, n. 63-64, p. 169-186, 2006.

EAGLETON, Terry. Teoria da literatura: uma introdução. São Paulo: Martins Fontes, 2006.

JESUS, Carolina Maria de. Quarto de despejo: diário de uma favelada. São Paulo: Ática, 2006.

LEFEBVRE, Henry. La presencia y la ausencia: contribución a la teoría de las representaciones. México: FCE, 2006.

MARTÍN-BARBERO, Jesús. Dos meios às mediações: comunicação, cultura e hegemonia. Rio de Janeiro: UFRJ, 1997.

MUKAROVSKY, Jan. Escritos de estética y semiótica del arte. Barcelona: Gustavo Gili, 1977.

ROCHA, João Cezar de Castro. A guerra dos relatos no Brasil contemporâneo. Ou: a "dialética da marginalidade". Letras. Santa Maria: Programa de Pós-Graduação em Letras, n. 28 e 29, jan./dez. 2004.

SARLO, Beatriz. Tiempo pasado: cultura de la memoria y giro subjetivo. Una discusión. Buenos Aires: Siglo XXI, 2005.

VATTIMO, Gianni. A sociedade transparente. Lisboa: Edições 70, 1989.

VILLARRAGA, Fernando. Literatura marginal: o assalto ao poder da escrita. Estudos de Literatura Brasileira Contemporânea, Brasília, n. 24, p. 35-53, jul./dez. 2004.

WILLIAMS, Raymond. Marxismo y literatura. Barcelona: Ediciones Península, 1980. 